Canadian Journal of Medicine

WWW.CIKD.CA

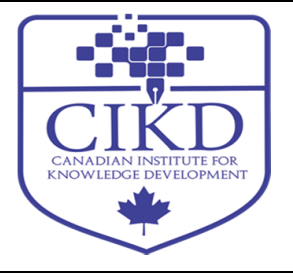

\title{
Identification and Expression of GFAP, YKL-40 and RBP4 in Serum as Noninvasive Biomarkers with Diagnostic and Prognostic Value for Detecting and Monitoring Glioma Patients
}

\author{
Fawziah M. Mohammed ${ }^{1}$, Nima Mohseni Kabir ${ }^{2 *}$ \\ ${ }^{1}$ Department of Medical Laboratory Sciences. Faculty of Allied Health Sciences. Kuwait University, \\ Kuwait \\ ${ }^{2} \mathrm{MD}$, Neurosurgeon, Tehran, Iran
}

Keywords:

Glioma, PCR, Analysis,

Marker, Expression

Received

05 June 2019

Received in revised form

03 October 2019

Accepted

30 November 2019

Correspondence: nmohseni790@gmail.com

\section{ABSTRACT}

The prognosis of patients with malignant glioma is poor. Identification of novel and effective biomarkers for this purpose has long been an important target. In this study, we investigated the role and expression of GFAP, YKL-40 and RBP4 in glioma patients. We evaluated the expression of markers above on glioma by ELISA, qRT-PCR, Western blot, Kaplan-Meier method, log-rank test and Cox proportional-hazard analysis. The median RBP4 level in serum sample of patients was $53.61 \pm 21.23 \mathrm{ng} / \mathrm{ml}$, while it was $13.07 \pm 10.31 \mathrm{ng} / \mathrm{ml}$ in control group. Moreover, the result revealed raised serum concentrations of YKL-40 and GFAP in patients as compared to controls. (The median level: $293.51 \pm 105.41$ versus $86.4 \pm 51.2 \mathrm{ng} / \mathrm{ml} ; 187.51 \pm 91.06$ versus $24.27 \pm$ $12.64 \mathrm{ng} / \mathrm{ml}$, respectively).And also, the transcriptional levels of RBP4 were determined to be increased in tumor tissue samples compared with control samples (mean \pm SD: $2.82 \pm 1.23$ vs. 0.75 $\pm 0.21, \mathrm{P}<0.001$ ), as well as transcriptional levels YKL-40 and GFAP were notably strong in glioma patients, comparable to that seen in control tissues (mean \pm SD: $5.33 \pm 1.13$ vs. $1.21 \pm 0.86 ; 3.05 \pm$ 1.37 vs. $0.68 \pm 0.34$; all $\mathrm{P}<0.001$ ). Consistent with the transcriptional levels, western blotting analysis also indicated that the RBP4, YKL-40 and GFAP proteins were increased in glioma tissues. Furthermore, the serum RBP4 level was not linked to advanced tumor grade, age, location or gender or with Karnofsky performance Status (KPS) (all P >0.05). The serum YKL-40 and GFAP levels were significantly higher in glioma patients with high tumor grades $(\mathrm{P}=0.001)$. The Kaplan-Meier analysis and the Log-rank test showed that high expression of YKL-40 and GFAP were associated with shorter survival (All $\mathrm{p}<0.001$ ), while RBP4 expression was not related to shorter survival (P $>0.05$ ). Our results showed that high serum expression of YKL-40 and GFAP were independent prognostic molecule biomarkers for poor prognosis prediction in glioma patients. 


\section{Introduction}

Glioma is the most common primary brain tumor and glioblastoma (GBM) is aggressive form of glioma in adults (Parker, Khong, Parkinson, Howell, \& Wheeler, 2015; Stupp et al., 2005). Despite recent progress in the treatment strategies such surgical techniques, radiation and chemotherapeutic methods, GBM is linked to the poor prognosis, with a median survival time of less than 15 months after diagnosis (Stupp et al., 2005; Stupp et al., 2009). Various gene alterations are considered as prognostic markers in glioma. The identification of biomarkers for glioma progression and prognosis are imminently required. Retinol binding protein 4 (RBP4), is encoded by the RBP4 gene and its' serum level enhanced in IR humans and mice (Yang et al., 2005). A few studies have evaluated association between serum levels of RBP4 and risk of cancer exists and has investigated its potential as a cancer biomarker (Abola et al., 2015; El-Mesallamy, Hamdy, Zaghloul, \& Sallam, 2013; Gray et al., 1995; Tsunoda et al., 2009).

YKL-40, a chitinase homolog (Chitinase 3-like 1/human cartilage glycoprotein 39) is a member of family 18 glycosyl hydrolases, and is located on chromosome 1q31-q32. It has been indicated that YKL-40 is implicated in cell proliferation, differentiation, apoptosis, inflammation and angiogenesis (Johansen, Schultz, \& Jensen, 2009; Volck et al., 1998). YKL-40 overexpression has been suggested to be correlated with poor prognosis of many kinds of cancers (Cintin, Johansen, Christensen, Price, \& Sorensen, 1999; Francescone et al., 2011; Qin et al., 2007; Xiao, Hassanein, Qun-Fang, Liu, Zheng, \& Chen, 2011). YKL-40 is highly expressed gene in gliomas as compared to normal brain (Tanwar, Gilbert, \& Holland; 2002). The high serum levels of the glycoprotein are associated with poor prognosis of various medical, inflammatory and tumor processes (Wang, Zhai, $\mathrm{Hu}$, Liu, Zhao, \& Xu, 2012). Several studies demonstrated that high serum concentrations of YKL40 were an independent prognostic factor of short overall survival in breast, kidney, colorectal, prostate, small cell lung cancers and ovarian cancer (Cintin et al., 1999; Geertsen, Johansen, von der Maase, Jensen, \& Price, 2003; Jensen, Johansen, \& Price, 2003; Johansen, Drivsholm, Price, \& Christensen, 2004; Dehn et al., 2003). The exact function of YKL-40 in development of cancers required further investigation.

Glial fibrillary acidic protein (GFAP) acts as a member of the cytoskeleton protein family and was strongly expressed in astrocytes (Eng, Ghirnikar, \& Lee, 2000). Serum levels of GFAP have been found to be increased after ischemic stroke, head trauma, and intracerebral hemorrhage $(6,7)$. It has been reported that GFAP serum level may be diagnostic biomarker for GBM (Jung et al., 2007). In this study, we evaluated the expression of GFAP, YKL-40 and RBP4 in glioma specimens and the association between the protein changes and prognosis was also analyzed.

\section{Materials and Methods}

\section{Patients and Tissue Samples}

A total of 84 glioma tissue samples were obtained from patients during surgery in various hospitals between 2004 and 2009. Furthermore, normal brain tissues collected from 20 patients who received epilepsy surgery. All tissues were immediately frozen in liquid nitrogen and stored at $-80{ }^{\circ} \mathrm{C}$. Diagnosis and classification of tumors were performed according to the World Health Organization criteria (Louis et al., 2007). The clinical and pathologic parameters were summarized in Table 1. Overall survival was defined as the period between the dates of surgery to the time of death. 


\section{RNA Extraction and Quantitative Real-time PCR}

Total RNA was extracted from the tissues using Trizol kit (Qiagen Germany) and was then reverse transcribed using QuantiTect Reverse Transcription Kit (Qiagen, Germany). The real-time RT PCR was performed using the SYBR Green Realtime PCR master mix. GAPDH was applied as an internal control. The primer sequences are as follow: RBP4 forward and reverse: 5'AGGAGAACTTCGACAAGGCT-3' and 5'-TTCCCAGTTGCTCAGAAGAC-3'; YKL-40 forward and reverse: 5'-CCT GCT CAG CGC AGC ACT GT-3' and 5'-GCT TTT GAC GCT TTC CTG GTC-3'-3'; GFAP forward and reverse: 5'-ATCGAGATCGCCACCT ACAG-3' and 5'CTCACATCACCACGTCCTTG-3'. GAPDH forward and reverse: 5'ACCCACTCCTCCACCTTTGA and 5'- CTGTTGCTGTAGCCAAATTCGT -3'. Moreover, relative expression levels of $\mathrm{mRNAs}$ were calibrated to that of GAPDH using the comparative cycle threshold (CT) method-fold change (2- $\Delta \Delta \mathrm{CT})$.

Table 1

The Correlation of Serum RBP4 Level with Clinical Parameters

\begin{tabular}{|c|c|c|c|c|}
\hline \multirow[t]{2}{*}{ Clinicopathological features } & \multirow[t]{2}{*}{ No. of cases $=84$} & \multicolumn{2}{|c|}{ RBP4 } & \multirow[t]{2}{*}{$\mathrm{P}$ value } \\
\hline & & Median & Range & \\
\hline \multicolumn{5}{|l|}{ Gender } \\
\hline Male & 36 & 50.12 & $35.30 \sim 63.78$ & \multirow[t]{2}{*}{ NS } \\
\hline Female & 48 & 44.29 & $28.51 \sim 55.5$ & \\
\hline \multicolumn{5}{|l|}{ Age } \\
\hline$\leq 40$ & 40 & 30.4 & $25.91 \sim 40.75$ & \multirow[t]{3}{*}{ NS } \\
\hline$>40$ & 44 & 35.17 & $28.41 \sim 49.13$ & \\
\hline \multicolumn{4}{|l|}{ Location } & \\
\hline Parenchyma & 51 & 43.04 & $41.72 \sim 50.7$ & \multirow{3}{*}{ NS } \\
\hline Ventricular & 33 & 45.11 & $40.31 \sim 56.19$ & \\
\hline \multicolumn{4}{|l|}{ WHO Grade } & \\
\hline I & 18 & 22.82 & $18.15 \sim 27.23$ & \multirow[t]{4}{*}{ NS } \\
\hline II & 30 & 28.12 & $23.02 \sim 35.46$ & \\
\hline III & 16 & 30.52 & $20.12 \sim 37.01$ & \\
\hline & 20 & 33.27 & $22.29 \sim 40.2$ & \\
\hline \multicolumn{5}{|l|}{$\begin{array}{l}\text { Karnofsky performance Status } \\
\text { (KPS) }\end{array}$} \\
\hline$<80$ & 51 & 33.67 & $26.05 \sim 50.24$ & \multirow[t]{2}{*}{ NS } \\
\hline$\geq 80$ & 33 & 29.41 & $20.15 \sim 43.02$ & \\
\hline
\end{tabular}

\section{Enzyme-Linked Immunosorbent Assay (ELISA)}

Serum levels of proteins was evaluated using a commercial Human ELIS A Kits (CHI3L1/YKL40 ELISA Kit and RBP4 Competitive ELISA Kit (Thermo Scientific ${ }^{\mathrm{TM}}$ ), Human GFAP ELISA Kit (R\&D Systems) according to the manufacturer's instructions. Moreover, the healthy volunteers were used as control. In brief, $25 \mu \mathrm{L}$ of the undiluted serum sample was added to corresponding wells. The plate was loaded with labeling reagent and incubated at $37^{\circ} \mathrm{C}$. The reactions were visualized in dark for $10 \mathrm{~min}$. All analysis was performed in triplicate.

\section{Western Blotting}

The Cells were lysed in RIPA buffer and, and the lysates were then harvested by centrifugation at $14,000 \mathrm{rpm}$ at for $30 \mathrm{~min}$. Protein samples were separated in a $12 \%$ sodium dodecyl sulfate polyacrylamide gels and then transferred on to a polyvinylidene fluoride membranes (PVDF). After blocking the non-specific binding sites with skim milk at room temperature for $2 \mathrm{~h}$, the membranes were then incubated with the primary antibodies (anti- RBP4, anti- YKL-40, antiGFAP). The protein levels were normalized using a mouse anti-human GAPDH monoclonal antibody. After washing with PBS containing $0.1 \%$ Tween 20 three times, the membranes were incubated with Horseradish peroxidase linked $\operatorname{IgG}$ as secondary antibodies for $2 \mathrm{~h}$ at room temperature. Immunoreactivity was visualized using the ECL detection systems. 


\section{Statistical Analysis}

$\chi^{2}$ test was applied to analyze the association between proteins expression and various clinicopathological. Overall survival curves were calculated by using the Kaplan-Meier method and the log-rank test was applied for its test. Cox proportional-hazard analysis was applied for univariate and multivariate assessment of cancer-specific. All statistical analyses were carried out using the SPSS statistics 19 and $\mathrm{P} \leq 0.05$ was considered statistically significant.

\section{Results}

\section{Serum Levels}

Serum levels of markers were determined by ELISA that is summarized in Table 1. Stratifying patients by average serum values, we evaluated the serum levels. Analysis of serum protein concentrations indicted that the median serum RBP4 level was elevated in $57(67.85 \%)$ patients with glioma compared control group $(\mathrm{P}<0.001)$. The median RBP4 level in serum sample of patients was $53.61 \pm 21.23 \mathrm{ng} / \mathrm{ml}$, while it was $13.07 \pm 10.31 \mathrm{ng} / \mathrm{ml}$ in control group. Moreover, the result revealed raised serum concentrations of YKL-40 and GFAP in patients as compared to controls. (The median level: $293.51 \pm 105.41$ versus $86.4 \pm 51.2 \mathrm{ng} / \mathrm{ml} ; 187.51 \pm 91.06$ versus $24.27 \pm 12.64 \mathrm{ng} / \mathrm{ml}$ ) (Figure 1, P <0.001). As matter of fact, an increase in YKL-40 and GFAP serum levels were observed in $50(59.52 \%)$ and $60(71.42 \%)$ of the patients.

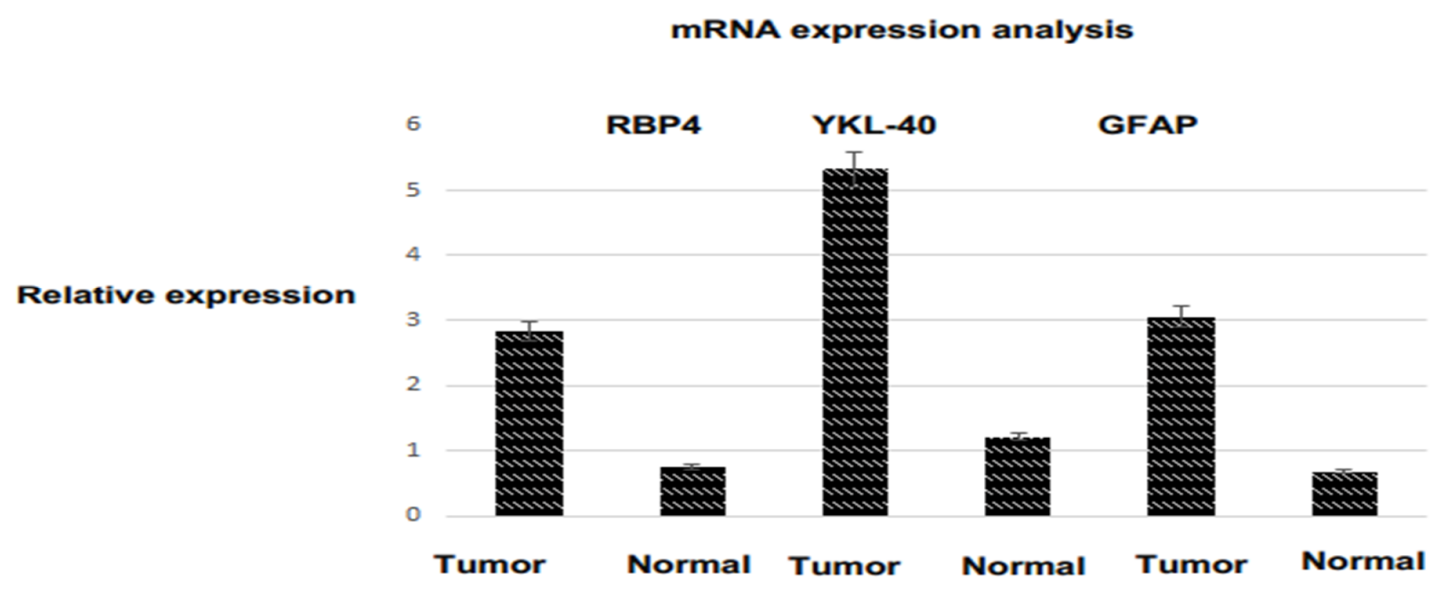

Figure 1. The mRNA levels of markers in gloma tissues and normal tissues

\section{MRNA Expression Analysis with qRT-PCR}

At second we checked mRNA levels of RBP4, YKL-40 and GFAP with qRT-PCR (Figure 1). The transcriptional levels of RBP4 were determined to be increased in tumor tissue samples compared with control samples (mean $\pm \mathrm{SD}: 2.82 \pm 1.23$ vs. $0.75 \pm 0.21, \mathrm{P}<0.001$ ).

We observed that transcriptional levels YKL-40 and GFAP were notably strong in glioma patients, comparable to that seen in control tissues (mean \pm SD: $5.33 \pm 1.13$ vs. $1.21 \pm 0.86$; $3.05 \pm 1.37$ vs. $0.68 \pm 0.34$; all $\mathrm{P}<0.001$ ). Consistent with the transcriptional levels, western blotting analysis also indicated that the RBP4, YKL-40 and GFAP proteins were increased in glioma tissues.

\section{Association between Serum Levels and Clinicopathological Parameters}

Table 1, 2 and 3 present the association between the high expression of RBP4, YKL-40 and GFAP with clinicopathological factors. 
Based on the categories that we defined in Table 1, the results showed that serum RBP4 level was not correlated with advanced tumor grade, age, location or gender or with Karnofsky performance Status (KPS) (all P $>0.05$ ).

Serum YKL-40 and GFAP levels varied among patients with different grades, and grade III and IV patients had markedly higher YKL-40 and GFAP than those with I or II grades. As matter of fact, serum YKL-40 and GFAP levels were significantly higher in glioma patients with high tumor grades (Both $\mathrm{P}=0.001)$. However, YKL-40 and GFAP serum concentrations were not associated with age, gender or location or with Karnofsky performance status (KPS), ( $\mathrm{P}>0.05)$.

Table 2

The Correlation of Serum YKL-40 Level with Clinical Parameters

\begin{tabular}{|c|c|c|c|c|}
\hline \multirow[t]{2}{*}{ Clinicopathological features } & \multirow[t]{2}{*}{ No. of cases $=84$} & \multicolumn{2}{|c|}{ YKL-40 } & \multirow[t]{2}{*}{$\mathrm{P}$ value } \\
\hline & & Median & Range & \\
\hline \multicolumn{5}{|l|}{ Gender } \\
\hline Male & 36 & 276.25 & $109.345 \sim 423.16$ & \multirow[t]{3}{*}{ NS } \\
\hline Female & 48 & 291.17 & $120.64 \sim 451.23$ & \\
\hline \multicolumn{4}{|l|}{ Age } & \\
\hline$\leq 40$ & 40 & 230.27 & $100.22 \sim 377.82$ & \multirow[t]{2}{*}{ NS } \\
\hline$>40$ & 44 & 252.12 & $132.4 \sim 391.59$ & \\
\hline \multicolumn{5}{|l|}{ Location } \\
\hline Parenchyma & 51 & 301.08 & $183.45 \sim 491.4$ & \multirow[t]{3}{*}{ NS } \\
\hline Ventricular & 33 & 287.56 & $162.78 \sim 436.1$ & \\
\hline \multicolumn{4}{|l|}{ WHO Grade } & \\
\hline I & 18 & 254.45 & $123.15 \sim 320.16$ & \multirow[t]{4}{*}{0.001} \\
\hline II & 30 & 272.81 & $133.88 \sim 341.34$ & \\
\hline III & 16 & 337.75 & $182.04 \sim 461.04$ & \\
\hline IV & 20 & 418.23 & $251.72 \sim 552.2$ & \\
\hline \multicolumn{5}{|c|}{ Karnofsky performance Status (KPS) } \\
\hline$<80$ & 51 & 313.12 & $213.07 \sim 427.73$ & \multirow[t]{2}{*}{ NS } \\
\hline$\geq 80$ & 33 & 325.1 & $233.46 \sim 439.48$ & \\
\hline
\end{tabular}

Table 3

The Correlation of Serum GFAP Level with Clinical Parameters of Patients

\begin{tabular}{|c|c|c|c|c|}
\hline \multirow{2}{*}{ Clinicopathological features } & \multirow{2}{*}{ No. of cases $=84$} & \multicolumn{2}{|c|}{ GFAP } & \multirow[t]{2}{*}{$\mathrm{P}$ value } \\
\hline & & Median & Range & \\
\hline \multicolumn{5}{|l|}{ Gender } \\
\hline Male & 36 & 161.21 & $70.4 \sim 282.43$ & \multirow[t]{3}{*}{ NS } \\
\hline Female & 48 & 184.83 & 85. $06 \sim 291.16$ & \\
\hline \multicolumn{4}{|l|}{ Age } & \\
\hline$\leq 40$ & 40 & 201.5 & $88.75 \sim 315.04$ & \multirow[t]{3}{*}{ NS } \\
\hline$>40$ & 44 & 173 & 73.54 294 & \\
\hline \multicolumn{4}{|l|}{ Location } & \\
\hline Parenchyma & 51 & 165.58 & $78.7 \sim 177.69$ & \multirow[t]{3}{*}{ NS } \\
\hline Ventricular & 33 & 180.22 & $85.32 \sim 189.34$ & \\
\hline \multicolumn{4}{|l|}{ WHO Grade } & \\
\hline I & 18 & 162.87 & $69.84 \sim 170.73$ & \multirow[t]{4}{*}{0.001} \\
\hline II & 30 & 186.62 & 84. $57 \sim 204.64$ & \\
\hline III & 16 & 206.11 & $121.74 \sim 283.3$ & \\
\hline & 20 & 240.38 & $174.79 \sim 339.27$ & \\
\hline \multicolumn{5}{|l|}{ Karnofsky performance Status (KPS) } \\
\hline$<80$ & 51 & 190.29 & $86.74 \sim 210.46$ & \multirow[t]{2}{*}{ NS } \\
\hline$\geq 80$ & 33 & 29.41 & $94.63 \sim 230.17$ & \\
\hline
\end{tabular}

\section{Correlation Analysis of Serum Levels and Prognosis of Patients}

Kaplan-Meier curves of patients with increased YKL-40 and GFAP suggested that there was a significant difference in survival times between groups. As matter of fact, the Kaplan-Meier analysis and the Log-rank test demonstrated that the patients with high expression of YKL-40 and GFAP exhibited shorter survival time than those with low levels (All $\mathrm{p}<0.001$; Figure 3 and 4). But RBP4 expression was not found to be associated with shorter survival $(\mathrm{P}>0.05$; Figure 2). 


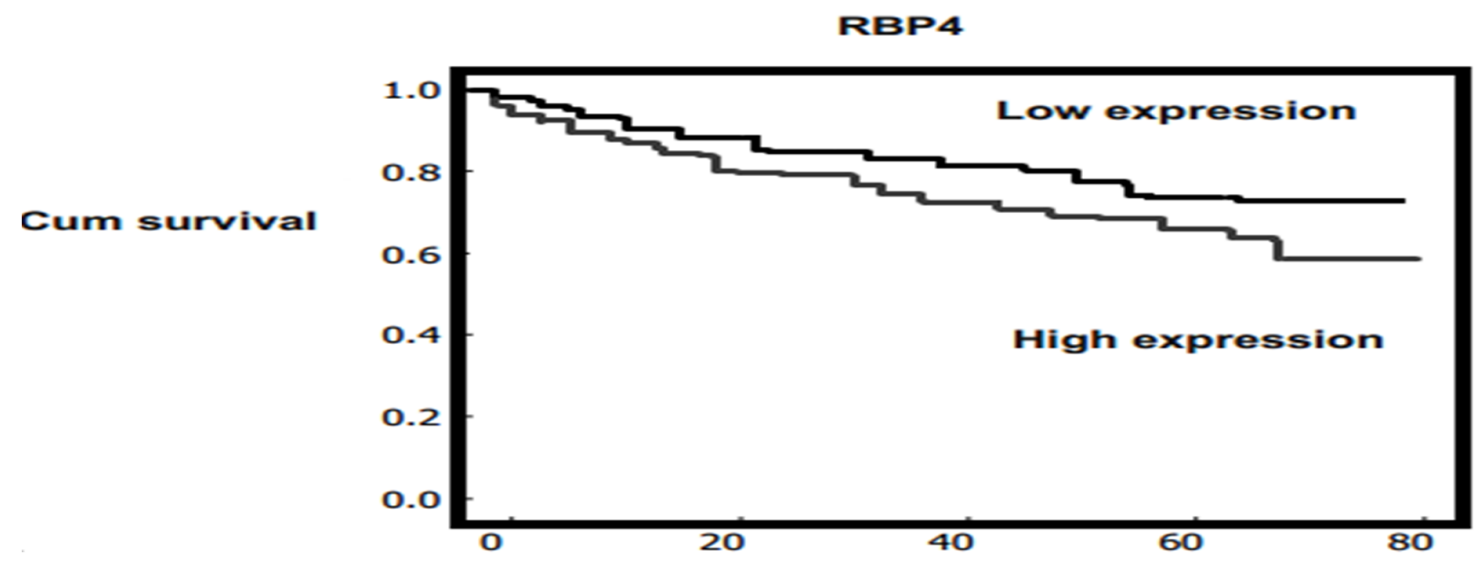

Figure 2. Kaplan-Meier postoperative survival curve was plotted for correlation of RBP4 with survival of glioma patients $(\mathrm{p}>0.05)$

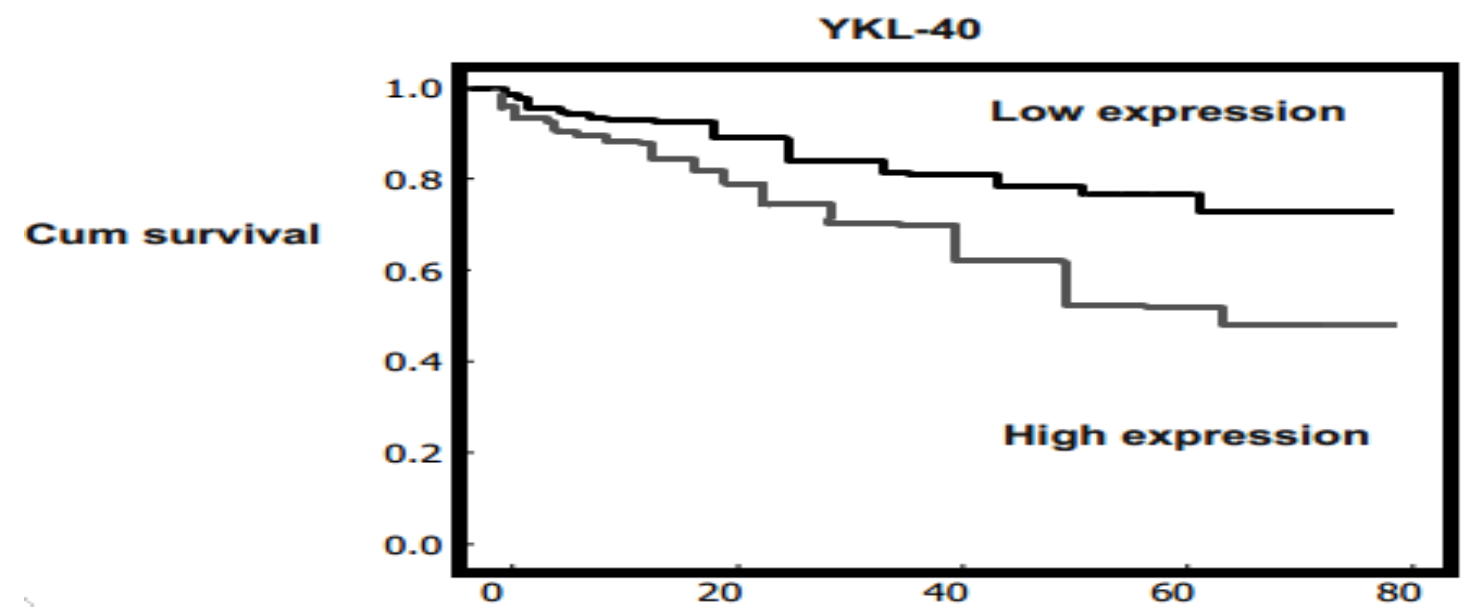

Figure 3. Kaplan-Meier postoperative survival curve was plotted for of YKL-40 with survival of glioma patients $(\mathrm{p}<0.001)$

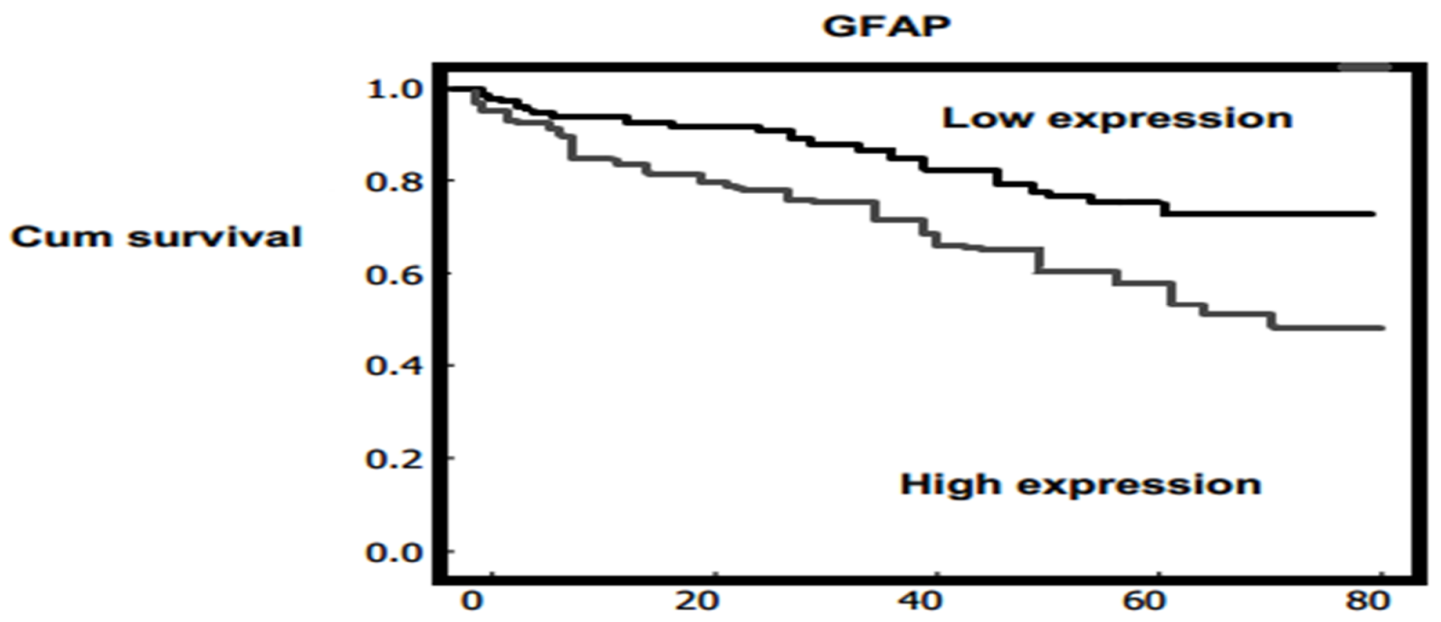

Figure 4. The association between GFAP expression and overall survival in patients $(\mathrm{p}<0.001)$

To find whether mentioned markers could be a useful prognostic assessment factor for glioma, Cox multivariate regression analysis clearly showed that high serum expression of YKL-40 and GFAP were independent prognostic molecule biomarkers for poor prognosis in glioma patients (Table 4). 
Table 4

Univariate and Multivariate Cox Regression Analyses of Overall Survival

\begin{tabular}{|c|c|c|c|c|c|c|}
\hline \multirow{2}{*}{$\begin{array}{l}\text { Clinicopathological } \\
\text { parameters }\end{array}$} & \multicolumn{3}{|c|}{ Univariate analysis } & \multicolumn{3}{|c|}{ Multivariate analysis } \\
\hline & Hazard ratio & $95 \% \mathrm{CI}$ & $P$ & Hazard ratio & $95 \% \mathrm{CI}$ & $P$ \\
\hline Gender & 0.72 & $0.545-1.238$ & 0.613 & - & - & - \\
\hline Age & 0.83 & $0.623-1.36$ & 0.575 & - & - & - \\
\hline Location & 1.07 & $1.12-1.573$ & 0.452 & - & - & - \\
\hline WHO Grade & 3.2 & $2.416-5.31$ & $<0.001$ & 2.332 & $1.242-3.523$ & 0.018 \\
\hline Karnofsky performance Status (KPS) & 1.37 & $1.03-1.62$ & 0.315 & - & - & - \\
\hline RBP4 expression & 3.43 & $2.73-5.83$ & $<0.001$ & 2.73 & $1.534-3.68$ & 0.02 \\
\hline YKL-40 expression & 2.86 & $1.51-4.73$ & $<0.001$ & 2.45 & $1.24-3.19$ & 0.028 \\
\hline GFAP expression & 1.18 & $1.28-1.61$ & 0.341 & - & - & - \\
\hline
\end{tabular}

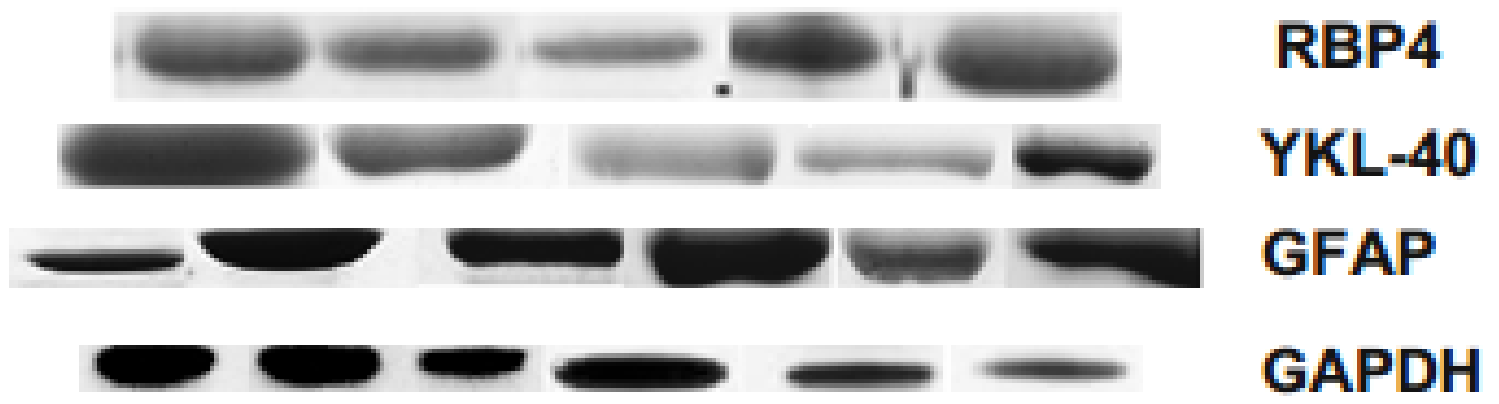

Figure 5. Western blotting analysis of proteins in tumor tissues. GAPDH was used as a loading control

\section{Discussion}

In the present study, the median serum RBP4 level was increased in patients with glioma compared control group. The transcriptional levels of RBP4 were upregulated in glioma tissue samples as compared to control samples. Our findings demonstrated that higher RBP4 serum expression was not correlated with tumor grade, location, age or gender or with KPS.

Liver is the major resource of RBP4 secretion in normal body. To-date, few studies indicated that the serum levels of RBP4 may be associated with the risk of cancer (Abola et al., 2015; ElMesallamy et al., 2013; Gray et al., 1995; Tsunoda et al., 2009). It has been showed that RBP4 protein was increased in hepatocellular carcinoma cell lines than that in normal liver cell line and its expression was liked to metastatic potential. Serum RBP4 levels were also correlated with overall survival and disease-free survival of patients with hepatocellular carcinoma (Wang et al., 2011). It has been revealed that RBP4 were increased in pancreatic cancer patients compared to controls (El-Mesallamy et al., 2013). Furthermore, RBP4 mRNA was underexpressed in HCC tissue than that of non-cancerous hepatitis tissue (Kinoshita \& Miyata, 2002). In obesity and in patients with MS, serum RBP4 was found to be linked to insulin resistance and circulating insulin level (Graham et al., 2005). It has been revealed that insulin may play an important role in carcinogenesis (Goodwin et al., 2002). In obesity or in patients with diabetes, RBP4 has been found to be as key upstream regulator of insulin resistance and inducer of elevated circulating insulin. However, further studies are required to identify the functional role of RBP4 in cancer development.

The result revealed that serum concentrations of YKL-40 were elevated in patients as compared to controls. Also, we observed that transcriptional levels YKL-40 was notably upregulated in glioma patients, comparable to that seen in control tissues. Several independent 
studies reported that YKL-40 in serum was increased in many kinds of carcinomas, such as breast, colorectum, prostate, hepatocellular carcinoma, brain, and blood (Bergmann, Johansen, Klausen, Mylin, Kristensen, \& Kjeldsen , 2005; Cintin et al., 1999; Francescone et al., 2011; Hogdall et al., 2003; Jensen et al., 2003; Nigro et al., 2005; Qin et al., 2007; Xiao et al., 2011). We found that serum YKL-40 levels were increased in grades III and IV patients than those with I or II grades. YKL-40 has been demonstrated to be one of the most overexpressed genes in glioblastoma (Shostak et al., 2003). Serum levels of YKL-40 were found to be associated with cancer aggressiveness (Jensen et al., 2003;). It has been previously indicated that high YKL-40 serum concentrations were significantly related to invasive lobular carcinoma, TMN stage III, lymph node metastases, and death. In accordance with our findings, Steponaitis et al (Nigro et al., 2005) indicated that mRNA expression of YKL-40 was evidently higher in glioblastoma tissues and patients with high YKL-40 expression had a shorter overall survival. These increased levels have also been observed to be linked to poorer survival of many kinds of cancer patients (Bergmann et al., 2005; Cintin et al., 1999; Francescone et al., 2011; Hogdall et al., 2003; Jensen et al., 2003; Nigro et al., 2005; Qin et al., 2007; Xiao et al., 2011).

In this study, shorter overall survival was correlated with serum expression of YKL-40, these findings are consistent with results in glioblastoma patients of Steponaitis and breast cancer (Nigro et al., 2005; Wang et al., 2012). Pair-wise combinations of markers in patients with glioblastoma showed that YKL-40 as prognostically important, providing patients with YKL-40-negative tumors with the best prognosis (Rousseau et al., 2006). According to the current evidences, it can be interpreted that YKL-40 serum concentrations may be a consistent biomarker of a specific patient disease progression.

Our result showed that serum concentrations of GFAP were increased in patients as compared to controls. Furthermore, mRNA levels of GFAP were detected to be upregulated in tumor tissue samples compared with control samples.

In the present study, serum GFAP levels varied among different grades, and patients with grades III and IV had markedly higher GFAP compared with other grades. GFAP serum level may be diagnostic biomarker for GBM (24). Increasing evidence demonstrated that serum levels of GFAP are increased in primary High-grade gliomas prior to surgical resection, indicating that serum GFAP can be a diagnostic biomarker (Brommeland, Rosengren, Fridlund, Hennig, \& Isaksen, 2007; Husain, Savage, \& Grossman, 2012; Jung et al., 2007). A previous study showed that serum levels of GFAP are associated with tumor volume in patients with high-grade gliomas. They indicated that GFAP can be a reliable biomarker in patients with high-grade gliomas (Brommeland et al., 2007). The association of serum GFAP to tumor burden in recurrent High-grade gliomas is of interest and indicates that serum GFAP may be a biomarker for tumor recurrence (Kiviniemi et al., 2015). In addition, GFAP level has been showed to be linked to IDH1 mutation status in high-grade gliomas and IDH1 mutation an important prognostic marker for a favorable outcome in gliomas than their IDH1 mutation negative counterparts (Horbinski, 2013). Association between high serum GFAP and IDH1 mutation-negative HGGs indicated serum GFAP correlation with high-grade gliomas (Kiviniemi et al., 2015). In our study, the Kaplan-Meier analysis and the Log-rank test suggested that the patients with high expression of GFAP had shorter survival time than those with low levels. 
A previous study didn't find significant association between more favorable overall survival in GBM patients and increased serum GFAP levels (Ilhan-Mutlu et al., 2013). On the other hand, it has been found that high serum GFAP correlates with poor progression-free survival (PFS), (Kiviniemi et al., 2015). However, a longitudinal follow-up with a larger patient population is required to identify the association of serum GFAP with clinical outcome. Taken together, Cox multivariate regression analysis indicated that high serum expression of YKL-40 and GFAP can be independent prognostic biomarkers for poor prognosis in glioma patients.

\section{References}

Abola, M. V., Thompson, C. L, Chen, Z., Chak, A., Berger, N. A, Kirwan, J. P, \& Li, L. (2015). Serum levels of retinol-binding protein 4 and risk of colon adenoma. Endocrine-Related Cancer, 22(2), L1-L4.

Bergmann, O. J, Johansen, J. S, Klausen, T. W, Mylin, A. K, Kristensen, J. S, \& Kjeldsen, E. (2005). High serum concentration of YKL-40 is associated with short survival in patients with acute myeloid leukemia. Clinical Cancer Research, 11(24), 86448652.

Brommeland, T., Rosengren, L., Fridlund, S., Hennig, R., \& Isaksen, V. (2007). Serum levels of glial fibrillary acidic protein correlate to tumour volume of high-grade gliomas. Acta Neurologica Scandinavica, 116(6), 380-38427.

Cintin, C., Johansen, J. S., Christensen, I. J., \& Price, P. A. (1999). Sorensen S. Serum YKL-40 and colorectal cancer. British Journal of Cancer, 79(9), 1494-1499.

Dehn, H., Hogdall, E. V., Johansen, J. S., Jorgensen, M., Price, P. A., Engelholm, S. A., \& Hogdall, C. K. (2003). Plasma YKL $\square$ 40, as a prognostic tumor marker in recurrent ovarian cancer. Acta Obstetricia et Gynecologica Scandinavica, 82(3), $287-293$.

El-Mesallamy, H. O., Hamdy, N. M., Zaghloul, A. S., \& Sallam, A. M. (2013). Clinical value of circulating lipocalins and insulinlike growth factor axis in pancreatic cancer diagnosis. Pancreas, 42(1), 149-154.

Eng, L. F, Ghirnikar, R. S, \& Lee, Y. L. (2000). Glial fibrillary acidic protein: GFAP-thirty-one years (1969-2000). Neurochemical Research, 25(9-10), 1439-1451.

Francescone, R. A., Scully, S., Faibish, M., Taylor, S. L., Oh, D., Moral, L., ... \& Shao, R. (2011). Role of YKL-40 in the angiogenesis, radioresistance, and progression of glioblastoma. Journal of Biological Chemistry, 286(17), 15332-15343.

Geertsen, P., Johansen, J. S., Von der Maase, H., Jensen, B. V., \& Price, P. A. (2003). High pretreatment serum level of YKL-40 is related to short survival in patients with advanced renal cell carcinoma treated with high-dose continuous intravenous infusion of interleukin-2. In Meeting Proceedings of American Society for Clinical Oncology ASCO (Vol. 22).

Graham, T. E., Yang, Q., Blüher, M., Hammarstedt, A., Ciaraldi, T. P., Henry, R. R., ... \& Kahn, B. B. (2006). Retinol-binding protein 4 and insulin resistance in lean, obese, and diabetic subjects. New England Journal of Medicine, 354(24), $2552-2563$.

Gray, I. C., Phillips, S. M., Lee, S. J., Neoptolemos, J. P., Weissenbach, J., \& Spurr, N. K. (1995). Loss of the chromosomal region 10q23-25 in prostate cancer. Cancer research, 55(21), 4800-4803.

Goodwin, P. J., Ennis, M., Pritchard, K. I., Trudeau, M. E., Koo, J., Madarnas, Y., ... \& Hood, N. (2002). Fasting insulin and outcome in early-stage breast cancer: results of a prospective cohort study. Journal of Clinical Oncology, 20(1), 42-51.

Hogdall, E. V., Johansen, J. S., Kjaer, S. K., Price, P. A., Christensen, L., Blaakær, J., ... \& Hogdall, C. K. (2003). High plasma YKL-40 level in patients with ovarian cancer stage III is related to shorter survival. Oncology Reports, 10(5), 1535-1538.

Horbinski, C. (2013). What do we know about IDH1/2 mutations so far, and how do we use it? Acta Neuropathologica, 125(5), 621-636.

Husain, H., Savage, W., Grossman, S. A., Ye, X., Burger, P. C., Everett, A., ... \& Holdhoff, M. (2012). Pre-and post-operative plasma glial fibrillary acidic protein levels in patients with newly diagnosed gliomas. Journal of Neuro-oncology, 109(1), 123127.

Ilhan-Mutlu, A., Wagner, L., Widhalm, G., Wöhrer, A., Bartsch, S., Czech, T., ... \& Base, W. (2013). Exploratory investigation of eight circulating plasma markers in brain tumor patients. Neurosurgical Review, 36(1), 45-56.

Jensen, B. V., Johansen, J. S., \& Price, P. A. (2003). High levels of serum HER-2/neu and YKL-40 independently reflect aggressiveness of metastatic breast cancer. Clinical Cancer Research, 9(12), 4423-4434.

Johansen, J. S., Drivsholm, L., Price, P. A., \& Christensen, I. J. (2004). High serum YKL-40 level in patients with small cell lung cancer is related to early death. Lung Cancer, 46(3), 333-340.

Johansen, J. S., Schultz, N. A., \& Jensen, B. V. (2009). Plasma YKL-40: a potential new cancer biomarker? Future Oncology, 5(7), $1065-1082$. 
Jung, C. S., Foerch, C., Schänzer, A., Heck, A., Plate, K. H., Seifert, V., ... \& Sitzer, M. (2007). Serum GFAP is a diagnostic marker for glioblastoma multiforme. Brain, 130(12), 3336-3341.

Kinoshita, M., \& Miyata, M. (2002). Underexpression of mRNA in human hepatocellular carcinoma focusing on eight loci. Hepatology, 36(2), 433-438.

Kiviniemi, A., Gardberg, M., Frantzén, J., Parkkola, R., Vuorinen, V., Pesola, M., \& Minn, H. (2015). Serum levels of GFAP and EGFR in primary and recurrent high-grade gliomas: correlation to tumor volume, molecular markers, and progression-free survival. Journal of Neuro-oncology, 124(2), 237-245.

Louis, D. N., Ohgaki, H., Wiestler, O. D., Cavenee, W. K., Burger, P. C., Jouvet, A., ... \& Kleihues, P. (2007). The 2007 WHO classification of tumours of the central nervous system. Acta Neuropathologica, 114(2), 97-109.

Nigro, J. M., Misra, A., Zhang, L., Smirnov, I., Colman, H., Griffin, C., ... \& Yung, W. A. (2005). Integrated array-comparative genomic hybridization and expression array profiles identify clinically relevant molecular subtypes of glioblastoma. Cancer Research, 65(5), 1678-1686.

Parker, N. R., Khong, P., Parkinson, J. F., Howell, V. M., \& Wheeler, H. R. (2015). Molecular heterogeneity in glioblastoma: Potential clinical implications. Frontiers in Oncology, 5, 55.

Qin, W., Zhu, W., Schlatter, L., Miick, R., Loy, T. S., Atasoy, U., ... \& Sauter, E. R. (2007). Increased expression of the inflammatory protein YKL $\square 40$ in precancers of the breast. International Journal of Cancer, 121(7), 1536-1542.

Rousseau, A., Nutt, C. L., Betensky, R. A., Iafrate, A. J., Han, M., Ligon, K. L., ... \& Louis, D. N. (2006). Expression of oligodendroglial and astrocytic lineage markers in diffuse gliomas: use of YKL-40, ApoE, ASCL1, and NKX2-2. Journal of Neuropathology and Experimental Neurology, 65(12), 1149-1156.

Shostak, K., Labunskyy, V., Dmitrenko, V., Malisheva, T., Shamayev, M., Rozumenko, V., ... \& Kavsan, V. (2003). HC gp-39 gene is upregulated in glioblastomas. Cancer Letters, 198(2), 203-210.

Stupp, R., Mason, W. P., Van Den Bent, M. J., Weller, M., Fisher, B., Taphoorn, M. J., ... \& Curschmann, J. (2005). Radiotherapy plus concomitant and adjuvant temozolomide for glioblastoma. New England Journal of Medicine, 352(10), 987-996.

Stupp, R., Hegi, M. E., Mason, W. P., Van Den Bent, M. J., Taphoorn, M. J., Janzer, R. C., ... \& Hau, P. (2009). Effects of radiotherapy with concomitant and adjuvant temozolomide versus radiotherapy alone on survival in glioblastoma in a randomised phase III study: 5-year analysis of the EORTC-NCIC trial. The Lancet Oncology, 10(5), 459-466.

Tanwar, M. K., Gilbert, M. R., \& Holland, E. C. (2002). Gene expression microarray analysis reveals YKL-40 to be a potential serum marker for malignant character in human glioma. Cancer Research, 62(15), 4364-4368.

Tsunoda, S., Smith, E., De Young, N. J., Wang, X., Tian, Z. Q., Liu, J. F., ... \& Drew, P. A. (2009). Methylation of CLDN6, FBN2, RBP1, RBP4, TFPI2, and TMEFF2 in esophageal squamous cell carcinoma. Oncology Reports, 21(4), 1067-1073.

Volck, B., Price, P. A., Johansen, J. S., Sørensen, O., Benfield, T. L., Nielsen, H. J., ... \& Borregaard, N. (1998). YKL-40, a mammalian member of the chitinase family, is a matrix protein of specific granules in human neutrophils. Proceedings of the Association of American Physicians, 110(4), 351-360.

Wang, D., Zhai, B., Hu, F., Liu, C., Zhao, J., \& Xu, J. (2012). High YKL-40 serum concentration is correlated with prognosis of Chinese patients with breast cancer. PLoS One, 7(12), e51127.

Wang, D. D., Zhao, Y. M., Wang, L., Ren, G., Wang, F., Xia, Z. G., ... \& Chen, J. P. (2011). Preoperative serum retinol-binding protein 4 is associated with the prognosis of patients with hepatocellular carcinoma after curative resection. Journal of Cancer Research and Clinical Oncology, 137(4), 651-658.

Xiao, X. Q., Hassanein, T., Qun-Fang, L., Liu, W., Zheng, Y. H., \& Chen, J. (2011). YKL-40 expression in human hepatocellular carcinoma: a potential biomarker? Hepatobiliary and Pancreatic Diseases International, 10(6), 605-610.

Yang, Q., Graham, T. E., Mody, N., Preitner, F., Peroni, O. D., Zabolotny, J. M., ... \& Kahn, B. B. (2005). Serum retinol binding protein 4 contributes to insulin resistance in obesity and type 2 diabetes. Nature, 436(7049), 356-362. 